\title{
Catalytic hydrolysis of s-triazine compounds over $\mathrm{Al}_{2} \mathrm{O}_{3}$
}

\author{
Zhaoqi Zhan ${ }^{a}$, Martin Müllner ${ }^{b}$, Johannes A. Lercher ${ }^{a, *}$ \\ ${ }^{a}$ Faculty of Chemical Technology, University of Twente, P.O. Box 217, 7500 AE Enschede, The Netherlands \\ ${ }^{b}$ Chemie Linz G.m.b.H., St.-Peter-strasse 25, A-2021, Linz, Austria
}

\begin{abstract}
Hydrolysis of cyanuric acid, melamine, melem, atrazine and melamine-formaldehyde resin was found to be catalyzed by an $\mathrm{Al}_{2} \mathrm{O}_{3}$ catalyst. The reactions occur irreversibly with cleavage of the s-triazine ring between 240 and $450^{\circ} \mathrm{C}$. The s-triazine-ring is hydrolyzed to ammonia and carbon dioxide, and the substituted groups to the corresponding molecules by addition of hydrogen.
\end{abstract}

Keywords: Hydrolysis; s-Triazine; Aluminium oxide

\section{Introduction}

The 1,3,5-triazine-based chemicals (usually abbreviated as s-triazines) have found various applications in manufacture of polymers, dyes, pesticides and commodity chemicals. Atrazine (2-chloro-4-ethylamino-6-isopropylamine-s-triazine) and other chloro-s-triazines are widely used as pesticides and the leakage during the manufacture, transport and use of these and other s-triazines lead to their deposition in the soil and in water resources. Atrazine has been detected in groundwater [1] and, although its concentration was only in the parts per billion ( $\mathrm{ppb}$ ) range, it has been increasing constantly because of its resistance to biological degradation under natural conditions. The potential impact of this to our environment has been a cause of concern [2]

The aromatic rings of s-triazines are known for their high thermal stability and lower reactivity. For instance, heating melamine in vacuum leads

* Corresponding author. to its condensation to melam $\left(\mathrm{C}_{6} \mathrm{~N}_{11} \mathrm{H}_{9}\right)$, melem $\left(\mathrm{C}_{6} \mathrm{~N}_{10} \mathrm{H}_{6}\right)$ and melon $\left(\mathrm{C}_{6} \mathrm{~N}_{9} \mathrm{H}_{3}\right)$ at 360,400 and $500^{\circ} \mathrm{C}$, respectively [3]. The cleavage of its aromatic ring occurs only above $600^{\circ} \mathrm{C}$ and results in cyanamide $[3,4]$. Cyanuric acid decomposes to isocyanic acid above $350^{\circ} \mathrm{C}$ [5]. The reactions of s-triazines mainly involve only the substituted groups, while the aromatic ring remains intact. Hydrolysis of melamine [6], atrazine [7] and some chloro-s-triazines $[8,9]$ in aqueous acids and bases were reported to occur stepwise with the loss of one, two or all three substituted groups. Usually cyanuric acid is the final product. Degradation of atrazine by combined chemical and biological oxidation, the most widely studied approach for destruction of the compound $[10,11]$, can remove the alkyls and $\mathrm{Cl}$ from the molecules, but leaves the aromatic ring unaffected.

Recently, we observed that s-triazines could be completely hydrolyzed with cleavage of the aromatic ring in the presence of an alumina catalyst under relatively low temperatures. In this paper, 
the results of catalytic hydrolysis of cyanuric acid, melamine, melem, atrazine and melamine-formaldehyde are presented. The reactions were quantitatively studied by means of temperatureprogrammed hydrolysis ( $\mathrm{tph}$ ) and, on the basis of the results, their stoichiometric equations were established. In addition, kinetic parameters of the reactions were determined with selected compounds under isothermal reaction conditions.

\section{Experimental}

Melamine, melem, atrazine and melamine-formaldehyde resin were obtained from Chemie Linz, Austria and cyanuric acid from MERCK. The purity of all these compounds was higher than $98 \%$. Active $\mathrm{Al}_{2} \mathrm{O}_{3}$ with specific surface area of about $300 \mathrm{~m}^{2} \mathrm{~g}^{-1}$ (BET) from PROCATALYSE was used as the catalyst for the hydrolysis. This sample was calcined at $600^{\circ} \mathrm{C}$ for $3 \mathrm{~h}$ prior to use.

A flow micro-reactor system equipped with a QMG311 quadrupole mass spectrometer (MS) to analyze the composition of the gaseous products was employed. The reactor used was a quartz glass tube with an inner diameter of $5 \mathrm{~mm}$ and was heated by a tubular furnace equipped with a EUROTHERM temperature programmer. The gaseous samples were introduced from the reactor to the MS by a stainless steel capillary sampling system. A gas flow of high purity $\mathrm{He}$ was fed through a water saturator (at room temperature) prior to the reactor. The concentration of water in this reactive gas flow was about 3.2 vol.-\%. The total flow rate was $30 \mathrm{ml} / \mathrm{min}$.

The hydrolysis experiments were performed isothermally at the desired temperatures and by means of tph. After a short purging with the watercontaining He flow below $100^{\circ} \mathrm{C}$, the sample was heated quickly to the reaction temperatures for the isothermal reaction. The composition of the tail gas was recorded by mass spectroscopy each $30 \mathrm{~s}$ until the reaction was completed. Tph measurements were performed by heating the sample at a rate of $10^{\circ} \mathrm{C}$ per min from 80 to $600^{\circ} \mathrm{C}$. In these experiments, the solid s-triazines were either mixed mechanically with the catalysts prior to loading into the reactor or were loaded before the catalyst bed. In the latter case, the catalyst bed and the sample bed were usually heated separately. When the temperature of the sample bed was sufficiently high, the s-triazine sublimed and the vapor was brought to the catalyst bed by the carrier gas.

Ammonia, carbon dioxide (main products) and water in the gas flow were quantitatively determined by mass spectroscopy based on the mass peaks with $m / e 16,44$ and 18, respectively. Quantitative analysis of these gases were carried out according to their integrated peak areas in each measurement. The calibration for ammonia was achieved by temperature-programmed desorption of ammonia from H-ZSM-5 under He flow in the reaction system [12]. The calibration for carbon dioxide and water were based on quantitatively thermal decomposition of $\mathrm{KHCO}_{3}$ [13].

\section{Results and discussion}

\subsection{General feature of catalytic hydrolysis of s- triazines}

Fig. 1 shows the results of the tph of the mixtures of s-triazines and the $\mathrm{Al}_{2} \mathrm{O}_{3}$ catalyst. Hydrolysis of cyanuric acid, melamine and melem produced only ammonia and carbon dioxide. In addition to these products, hydrolysis of atrazine produced also fragments of the substituted groups (see Section 3.2).

The reaction of these compounds occurred at different temperatures. The maxima of the hydrolysis peaks appeared at $300,410,425$ and $440^{\circ} \mathrm{C}$ for cyanuric acid, melamine, melem and atrazine, respectively. The formation of all gaseous products and the consumption of water occurred in parallel with the temperature increase. This indicates that the hydrolysis of these compounds proceeds apparently in one step under the experimental conditions employed.

When the content of s-triazines in the mixed samples was relatively high, some solids were 

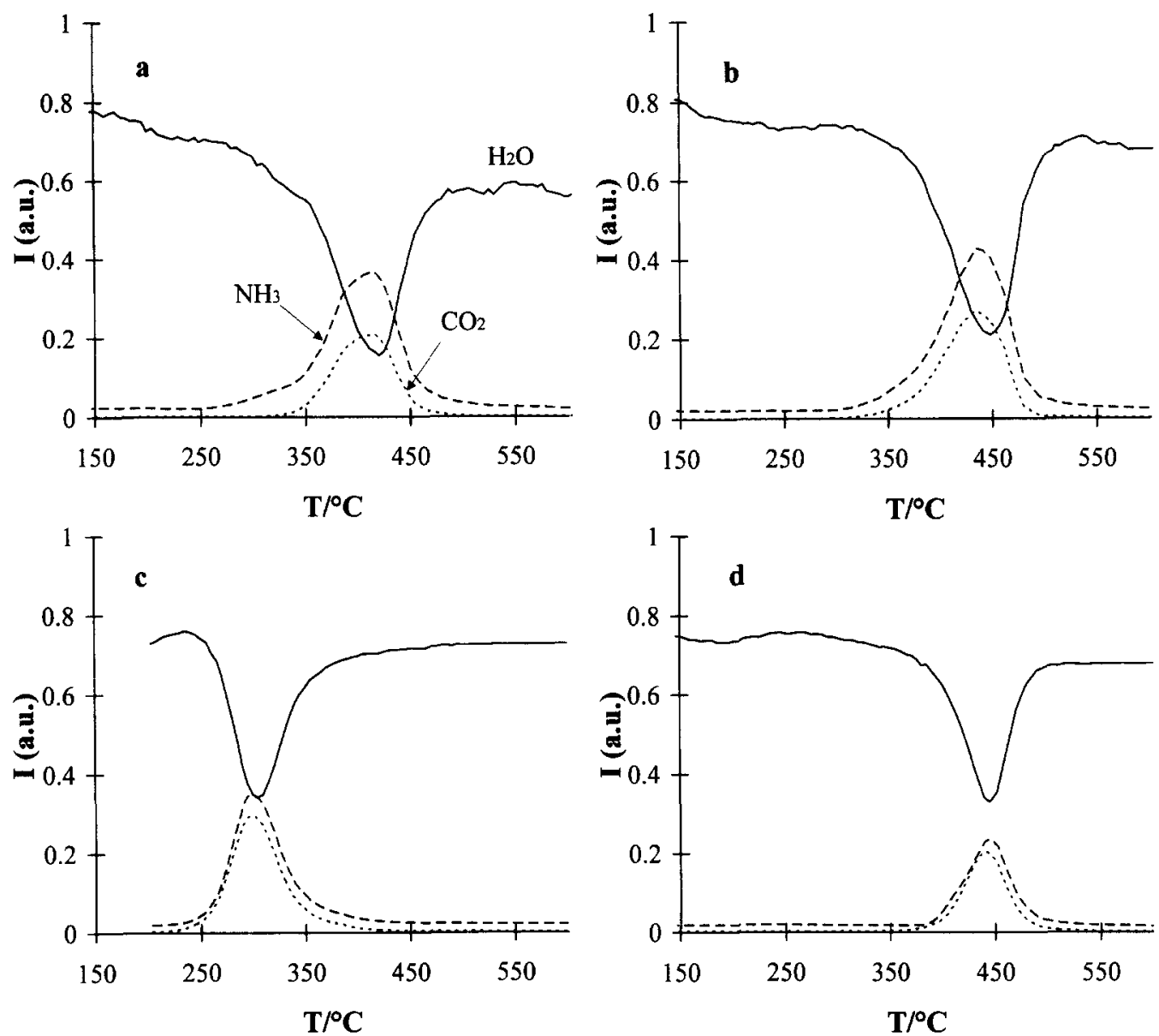

Fig. 1. Tph of mixed $5 \%$ melamine $/ \mathrm{Al}_{2} \mathrm{O}_{3}$ (a), $10 \%$ melem $/ \mathrm{Al}_{2} \mathrm{O}_{3}$ (b), $5 \%$ cyanuric acid $/ \mathrm{Al}_{2} \mathrm{O}_{3}$ (c) and $5 \%$ atrazine $/ \mathrm{Al}_{2} \mathrm{O}_{3}(\mathrm{~d})$.

found on the exit of the reactor after tph. Analysis of these solids by IR spectroscopy showed that they were unreacted s-triazines. This suggests that concentration limitations of these s-triazines in the mixtures for a complete hydrolysis exist. For cyanuric acid and melamine, this limitation was found to be about $5 \mathrm{wt}$. $\%$. It was about $20 \mathrm{wt} .-\%$ for melem and about only 1 wt. $-\%$ for atrazine.

The sublimation temperatures of these s-triazines are lower than their hydrolysis temperatures. For example, the difference for atrazine is as large as $205^{\circ} \mathrm{C}$. Due to the fact that only s-triazine adsorbed on the catalyst will be hydrolyzed at higher temperatures, the concentration limitations indicated above are speculated to be connected to the maximum amount of these compounds that will adsorb on the catalyst, the sorption constant and the concentration in the gas phase. These seems to be a complex interplay of these functions and we attribute the large value of the concentration limitation for melem to its slow sublimation during tph. Further evidence to this is seen in the kinetic measurements and shown below.

Catalytic hydrolysis of these s-triazines is essentially thermodynamically irreversible and, therefore, there is no thermodynamic limitation to the conversion. The concentration limitations of the hydrolysis observed with mixed samples are due to the existence of kinetic limitation, i.e., the rate of the chemical steps (e.g., chemisorption of s-triazine molecules on the active sites of the catalyst and their surface transformation) are slower than that of sublimation (or evaporation) of striazines in the case of the mixed samples. This leads to the escape of a fraction of unreacted striazine from the catalyst during the heating of the 




Fig. 2. Tph of mixed $10 \%$ melamine-formaldehyde resin $/ \mathrm{Al}_{2} \mathrm{O}_{3}$.

samples and therefore an incomplete conversion is obtained. If we could lower the sublimation rate of s-triazines and/or enhance the reaction rate of the hydrolysis, a complete conversion could be always obtained. This was proved with all s-triazines studied under the condition of separately heating the s-triazines (at lower temperatures) and the catalyst bed (at higher temperatures). For instance, when atrazine was evaporated at $180^{\circ} \mathrm{C}$ and the vapor passed through the catalyst bed which was kept at or above $440^{\circ} \mathrm{C}$ in He flow, the hydrolysis of atrazine was complete.

Melamine-formaldehyde resin (MF) was also hydrolyzed over $\mathrm{Al}_{2} \mathrm{O}_{3}$ catalysts under the same condition. The tph of a mixed $10 \% \mathrm{MF} / \mathrm{Al}_{2} \mathrm{O}_{3}$ is shown in Fig. 2. It can be seen that the hydrolysis started at $350^{\circ} \mathrm{C}$ and continued slowly up to $420^{\circ} \mathrm{C}$. Above $420^{\circ} \mathrm{C}$, the reaction rate increased rapidly and reached the maximum at $435^{\circ} \mathrm{C}$. The reaction continued until $600^{\circ} \mathrm{C}$ which was significantly higher than that of non-condensed s-triazines. This result suggests that the hydrolysis of melamine-formaldehyde resin over $\mathrm{Al}_{2} \mathrm{O}_{3}$ proceeds via a multi-step process.

\subsection{Products and stoichiometric equations of the hydrolysis}

The yields of the products $\left(\mathrm{NH}_{3}\right.$ and $\left.\mathrm{CO}_{2}\right)$ of hydrolysis from melamine and melem and the amounts of water consumed were determined with mixed samples under tph conditions. The results are shown in Fig. 3 and Fig. 4.

The hydrolysis of melamine and melem produced only ammonia and carbon dioxide, hence, the reactions can be described by Eqs. (1) and (2). According to these stoichiometric equations, the theoretical yields of the products and the consumption amounts of water were calculated and the values are included in Fig. 3 and Fig. 4 (dashed lines). It can be seen that the measured values are well in accordance with the theoretical values. The measured ratios of $\mathrm{NH}_{3} / \mathrm{CO}_{2}$ are also close to the theoretical values, i.e., 2 and 1.67 for melamine and melem, respectively. Hence, it can

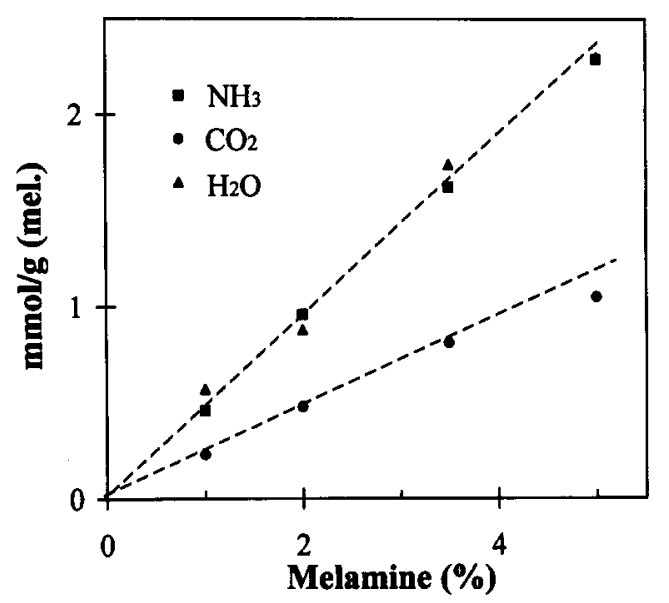

Fig. 3. The amounts of $\mathrm{NH}_{3}$ and $\mathrm{CO}_{2}$ produced and $\mathrm{H}_{2} \mathrm{O}$ consumed in hydrolysis of melamine over $\mathrm{Al}_{2} \mathrm{O}_{3}$ (points: measured; dashed lines: theoretical).

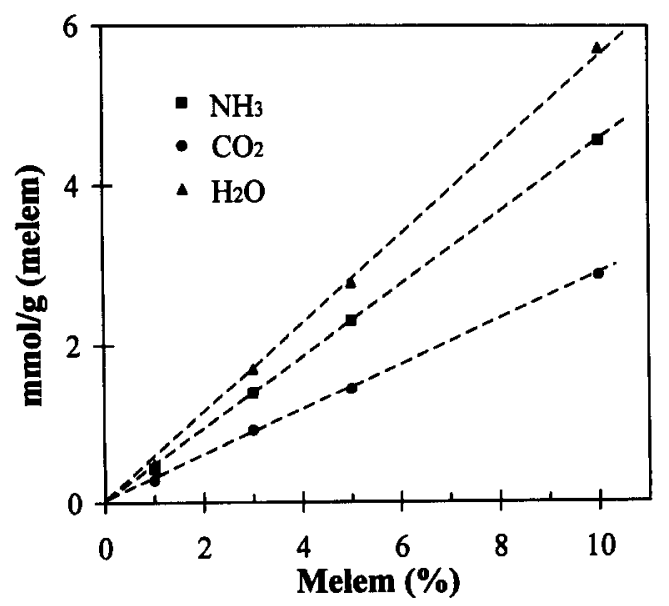

Fig. 4. The amounts of $\mathrm{NH}_{3}$ and $\mathrm{CO}_{2}$ produced and $\mathrm{H}_{2} \mathrm{O}$ consumed in hydrolysis of melem over $\mathrm{Al}_{2} \mathrm{O}_{3}$ (points: measured; dashed lines: theoretical). 
be concluded that hydrolysis of melamine and melem over $\mathrm{Al}_{2} \mathrm{O}_{3}$ is quantitative as described by Eqs. (1) and (2). The reactions are irreversible and are without formation of any by-products.



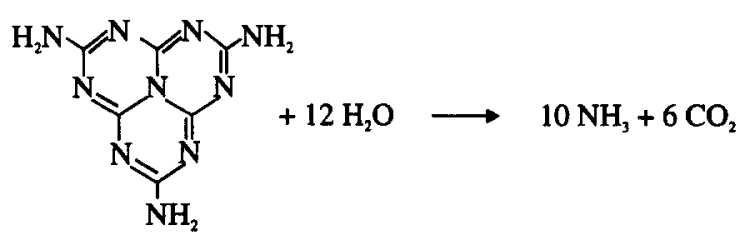<smiles>CC(C)CNC(=O)O</smiles>

Like melamine and melem, hydrolysis of cyanuric acid over $\mathrm{Al}_{2} \mathrm{O}_{3}$ is also quantitative and irreversible. The reaction can be described stoichiometrically by Eq. (3). The molar ratio of $\mathrm{NH}_{3} / \mathrm{CO}_{2}$ was confirmed to be unity by experiments.

Hydrolysis of atrazine over $\mathrm{Al}_{2} \mathrm{O}_{3}$ produced $\mathrm{NH}_{3}, \mathrm{CO}_{2}$ and the products from reaction of the substituted groups of the molecule, but there were no $\mathrm{Cl}$-containing compounds in the gas phase products. In addition to these gaseous products, some soluble white solids were found at the exit of the reactor and were confirmed to be $\mathrm{NH}_{4} \mathrm{Cl}$ by infrared spectroscopy. Fig. 5 shows the distributions of the products of atrazine hydrolysis at 440 and $500^{\circ} \mathrm{C}$. Because only $\mathrm{NH}_{3}$ and $\mathrm{CO}_{2}$ were quantitatively determined, the data for the other products in the figure represent only relative yields. But, this does not obstruct us to examine roughly the influence of the reaction temperature on the product distribution. It can be seen from Fig. 5 that at $440^{\circ} \mathrm{C}$, except for $\mathrm{NH}_{3}$ and $\mathrm{CO}_{2}$, the gaseous products contained $\mathrm{C}_{2} \mathrm{H}_{5} \mathrm{NH}_{2}, \mathrm{C}_{2} \mathrm{H}_{4}$,


Fig. 5. A comparison of product distributions of atrazine hydrolysis over $\mathrm{Al}_{2} \mathrm{O}_{3}$ at 440 and $500^{\circ} \mathrm{C}$ (shaded: relative values).

$\mathrm{C}_{3} \mathrm{H}_{6}$ and small amounts of $\mathrm{H}_{2}$. At $500^{\circ} \mathrm{C}$, $\mathrm{C}_{2} \mathrm{H}_{5} \mathrm{NH}_{2}$ disappeared, but $\mathrm{CH}_{3} \mathrm{CN}$ was formed together with the release of relatively large amounts of $\mathrm{H}_{2}$. The product distribution of the reaction at $600^{\circ} \mathrm{C}$ was similar to that at $500^{\circ} \mathrm{C}$, except for the formation of a small amount of $\mathrm{CO}$.

Assuming the reaction proceeds via a similar pathway as observed for melamine and cyanuric acid hydrolysis, the substituted groups of the molecule should be transformed to $\mathrm{HCl}, \mathrm{C}_{2} \mathrm{H}_{5} \mathrm{NH}_{2}$ and i- $\mathrm{C}_{3} \mathrm{H}_{7} \mathrm{NH}_{2}$ as primary products. However, only ethylamine was found in the products at $440^{\circ} \mathrm{C}$. Koubek et al. [14] reported that amines underwent disproportionation and deamination to form secondary amines and olefins on alumina catalysts at $400^{\circ} \mathrm{C}$. In our case, secondary amines were not present, but olefins (ethylene and propylene) were found in the products. This indicates that deamination of amines occurs on the catalyst. Acetonitrile is believed to be produced by dehydrogenation of ethylamine, because its amount increased with $\mathrm{H}_{2}$ as the reaction temperature 
increased. In addition, the amounts of solid product $\mathrm{NH}_{4} \mathrm{Cl}$ collected from the exit of the reactor ( $238 \pm 10 \mathrm{mg}$ per gram of atrazine) are in accordance with the theoretical yield of $\mathrm{NH}_{4} \mathrm{Cl}$ (i.e., $248 \mathrm{mg}$ per gram of atrazine) according to the molar content of chlorine in the atrazine molecule. This result suggests that all of the $\mathrm{HCl}$ formed in the primary reaction of atrazine hydrolysis was transformed to $\mathrm{NH}_{4} \mathrm{Cl}$. The overall reactions of atrazine hydrolysis over $\mathrm{Al}_{2} \mathrm{O}_{3}$ catalysts can be described by Eqs. (4)-(8).

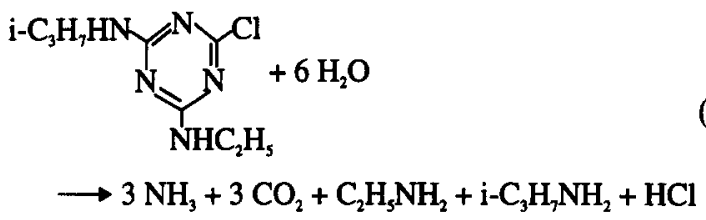

$\mathrm{C}_{2} \mathrm{H}_{5} \mathrm{NH}_{2} \rightarrow \mathrm{C}_{2} \mathrm{H}_{4}+\mathrm{NH}_{3}$

$\mathrm{i}-\mathrm{C}_{3} \mathrm{H}_{7} \mathrm{NH}_{2} \rightarrow \mathrm{i}-\mathrm{C}_{3} \mathrm{H}_{6}+\mathrm{NH}_{3}$

$\mathrm{C}_{2} \mathrm{H}_{5} \mathrm{NH}_{2} \rightarrow \mathrm{CH}_{3} \mathrm{CN}+2 \mathrm{H}_{2}$

$\mathrm{HCl}+\mathrm{NH}_{3} \rightarrow \mathrm{NH}_{4} \mathrm{Cl}(\mathrm{s})$

According to this reaction pathway, $\mathrm{CO}_{2}$ and $\mathrm{HCl}$ are produced only by the primary reaction (Eq. (4) ) of the hydrolysis. From the yields of $\mathrm{CO}_{2}$ (see Fig. 5) and $\mathrm{NH}_{4} \mathrm{Cl}$, it was concluded that the primary reaction was complete when the temperature was at or above $440^{\circ} \mathrm{C}$. The yield of ammonia and the ratio of $\mathrm{NH}_{3} / \mathrm{CO}_{2}$ depended on the secondary reactions (5)-(7). Theoretically, the ratio of $\mathrm{NH}_{3} / \mathrm{CO}_{2}$ must be between 0.67 and 1.33. The measured value of $\mathrm{NH}_{3} / \mathrm{CO}_{2}$, for example, was 1.16 for the reaction at $440^{\circ} \mathrm{C}$. From this value, the selectivity to deamination of amines (ethylamine and iso-propylamine) to ammonia and olefins was determined, i.e., $73 \%$ at $440^{\circ} \mathrm{C}$, increasing with the reaction temperature. Further estimation of selectivity of secondary reactions was not attempted.

Based on these results, a general stoichiometric equation of the primary reaction of hydrolysis of mono-ring s-triazines can be described by Eq. (9). The ring atoms, $\mathrm{N}$ and $\mathrm{C}$, are hydrolyzed to ammonia and carbon dioxide, respectively. The substituted groups are transformed to the corresponding molecules by addition of protons. Secondary reactions of the primary products depend on their chemical nature and the reaction conditions.

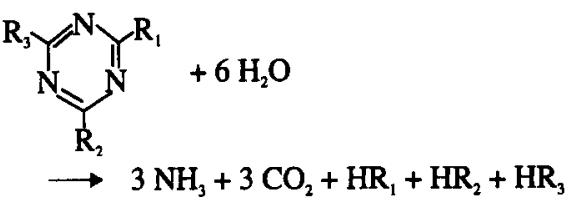

\subsection{Kinetic measurements}

The kinetic measurements of the hydrolysis were carried out with mixed melamine $/ \mathrm{Al}_{2} \mathrm{O}_{3}$ and melem $/ \mathrm{Al}_{2} \mathrm{O}_{3}$ at constant temperatures between 345 and $410^{\circ} \mathrm{C}$. After a short period of purging with $\mathrm{H}_{2} \mathrm{O} / \mathrm{He}$ flow at $200^{\circ} \mathrm{C}$, the sample was rapidly brought to the reaction temperatures and kept at the same temperatures until the end of the hydrolysis.

As shown in Fig. 6 and Fig. 7, the reaction rates of hydrolysis of melamine and melem over $\mathrm{Al}_{2} \mathrm{O}_{3}$ fit first and zero order kinetic equations, respectively. The rate constants of the reactions were derived from the plots of $\ln \left(C_{0}-C_{t}\right)$ vs. time and $\alpha$ (the reaction fraction) vs. time. These data and the activation energies which were estimated from Arrhenius plots are listed in Table 1 .

The mixed samples were prepared by mechanically dispersing the s-triazine solid among the catalyst particles at room temperature. This operation is not sufficient to cause a significant chem-

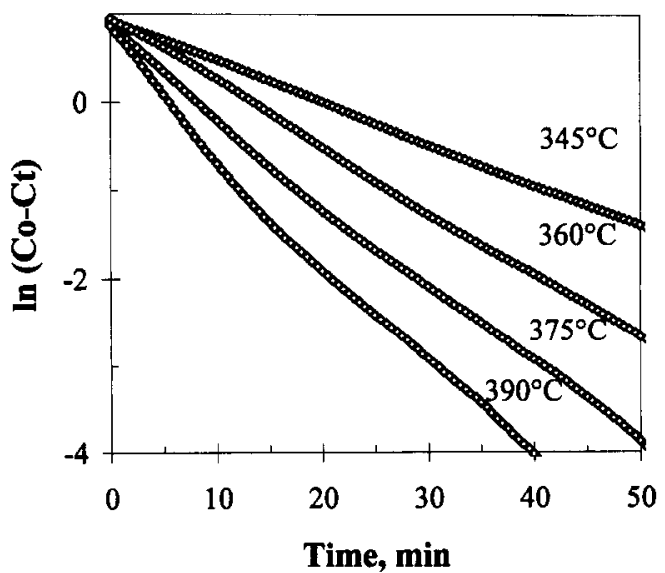

Fig. 6. Plot of $\ln \left(C_{0}-C_{t}\right)$ vs. reaction time of melamine hydrolysis over $\mathrm{Al}_{2} \mathrm{O}_{3}$ at various temperatures. 


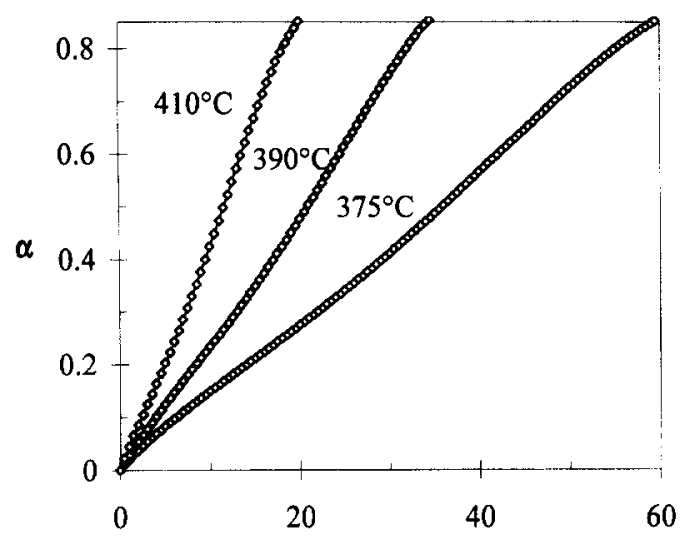

Time, min.

Fig. 7. Plot of the reaction fraction $(\alpha)$ vs. reaction time of melem hydrolysis over $\mathrm{Al}_{2} \mathrm{O}_{3}$ at various temperatures.

Table 1

Kinetic parameters of the hydrolysis of melamine and melem over $\mathrm{Al}_{2} \mathrm{O}_{3}$

\begin{tabular}{llllllll}
\hline $\begin{array}{l}\text { compound reaction } \\
\text { order }\end{array}$ & \multicolumn{4}{c}{$k \times 10^{3}\left[\mathrm{~min}^{-1}\right]$, at $\left[{ }^{\circ} \mathrm{C}\right]$} & $\begin{array}{l}E_{\mathrm{a}} \\
{\left[\mathrm{kJ} \mathrm{mol}^{-1}\right]}\end{array}$ \\
\hline $\begin{array}{l}\text { melamine } \\
\text { melem }\end{array}$ & 1 & 345 & 360 & 375 & 390 & 410 & \\
\hline
\end{tabular}

ical interaction between the compound and the catalyst. As the sample is heated to a certain temperature, the s-triazine in the samples starts to melt (or sublime) and then to diffuse towards the surface of the catalyst. These physical processes occur before the chemisorption and the reaction and might be the rate-controlling step if they take place at relatively high temperatures compared to the hydrolysis. Sublimation of melem occurs at a temperature close to that of its hydrolysis. Hence, we prefer to attribute the zero order kinetics of melem hydrolysis to the case that the reaction rate is controlled by the melting-diffusion step. Under this mechanism, the Arrhenius activation energy obtained will correspond to the sublimation heat of melem, i.e., $\Delta H_{\mathrm{sub}}^{0}=122 \mathrm{~kJ} / \mathrm{mol}$.

\section{Conclusions}

Hydrolysis of mono- and multi-ring s-triazines and melamine-formaldehyde resin with ringopening was catalyzed by active alumina. The reactions occur between 240 and $450^{\circ} \mathrm{C}$ and are irreversible. The aromatic ring of s-triazines is hydrolyzed to ammonia and carbon dioxide. The substituted groups are transformed to corresponding molecules by addition of hydrogen. This catalytic hydrolysis of s-triazines decreases dramatically the temperature needed for the cleavage of the s-triazine-ring.

\section{Acknowledgements}

Financial support for this work from ÖMVChemie Linz, Austria and the most valuable discussions with Dr. G. Stern (ÖMV-Chemie Linz) are gratefully acknowledged.

\section{References}

[1] S.Z. Cohen, C. Eiden and M.N. Lorber, ACS Symp. Ser. No. 315, (1986) 170.

[2] J. Henriet, L. Detroux and J.A. de Selsaten, Study of the Technical and Economic Aspects of Measures to Reduce Water Pollution Caused by the Discharge Atrazine, Bentazone and Chloroprene, Excoser (for the) European Commission, Luxembourg, 1994.

[3] H. May, J. Appl. Chem., June 9 (1959) 340.

[4] J.S. Mackay, US Patent 2656253 (1953).

[5] A. Schmidt, Monat. Chem., 101 (1970) 866.

[6] B. Bann and S. Miller, Chem. Rev., 58(1) (1958) 131.

[7] D.S. Gambel and S.U. Khan, Can. J. Chem., 66 (1988) 2605.

[8] S. Horrobin, J. Chem. Soc., (1963) 4130.

[9] E.M. Smolin and L. Rapoport, Chem. Hetercycl. Compod., 13 (1959) 272.

[10] P.C. Kearney, M.T. Muldoon, C.J. Somich, J.M. Ruth and D.J. Voaden, J. Agric. Food Chem., 36 (1988) 1301.

[11] J.P. Scott and D.F. Ollis, Environ. Progr., 14(2) (1995) 88.

[12] M. Stochenhuber, Ph.D Thesis, Technical University of Vienna, Vienna, 1994.

[13] J. Paulik and F. Paulik in Simultaneous Thermoanalytical Examination by Means of the Derivatograph, 1981, p. 67.

[14] Josef Koubek, Jiri Volf and Josef Pasek, J. Catal., 38 (1975) 385. 